\title{
The epidemiology of peritonitis caused by coagulase- negative staphylococci in continuous ambulatory peritoneal dialysis
}

\author{
H. A. LUDLAM, W. C. NOBLE*, R. R. MARPLESt, R. BAYSTON $¥$ and I. PHILLIPS
}

Department of Microbiology, UMDS, St Thomas' Hospital, London SE1 ' 'The Institute of Dermatology, UMDS, The Lambeth Hospital, London SE11; †The Staphylococcus Reference Unit, CPHL, 61 Colindale Avenue, London NW9; and $\ddagger$ Department of Paediatric Surgery, The Institute of Child Health, London WC1

\begin{abstract}
Summary. The epidemiology of 10 episodes of CAPD peritonitis caused by coagulasenegative staphylococci was studied. The infecting micro-organism was found in prospective skin swabs in six episodes, widely distributed and as the predominant, or equally predominant, organism at each site but was not detected in swabs taken more than 12 weeks before the episode of peritonitis; this suggests recent acquisition. Infecting strains were no more likely to be adherent or to produce slime than noninfecting strains, nor had they any other characteristic detected in our typing scheme that might lead to their detection before peritonitis developed.
\end{abstract}

\section{Introduction}

Peritonitis is the most important complication of continuous ambulatory peritoneal dialysis (CAPD) and coagulase-negative staphylococci are the commonest cause (Bint et al., 1987); the patient's skin has been assumed to be the source of infection. This hypothesis has been tested in two published studies. Sewell et al. (1982) prospectively swabbed the noses and exit sites of 30 patients undergoing CAPD or intermittent peritoneal dialysis, at monthly intervals over a 13-month period. Seven episodes of coagulase-negative staphylococcal peritonitis occurred in three patients, and indistinguishable strains were found on the skin beforehand in all cases. However, isolates were typed by biotyping with the scheme of Kloos and Schleifer (1975) only, and this scheme has been found to be poorly discriminatory (Parisi and Hamory, 1986; Hartstein et al., 1987). Thus, it is possible that skin and peritonitis strains deemed indistinguishable by Sewell et al. could have been differentiated by a more discriminatory typing scheme. Eisenberg et al. (1987) attempted to correct this deficiency by supplementing biotyping by the Kloos and Schleifer scheme with typing by plasmid profile. These workers also prospectively swabbed the noses and exit sites of their patients, at 6-weekly intervals over a period of 9 months. In contrast to the study of Sewell et al., the infecting strain was found on

Received 20 Feb. 1989; accepted 5 April 1989. prospective skin swabs in only three of the 20 episodes studied, but the authors conceded that inadequate skin sampling techniques and selection of single strains for typing by colonial morphology after incubation for only 2 days at $37^{\circ} \mathrm{C}$ may have underestimated the rate of carriage of distinct strains of coagulase-negative staphylococci.

The present study was designed to investigate the epidemiology of these infections, correcting the deficiencies of the earlier studies by employing both an effective typing scheme and adequate methods for sampling skin flora. We also wished to test the hypothesis that infecting strains were more likely to adhere to plastic and produce extracellular slime than non-infecting (skin) strains. These properties have been claimed to be markers of special pathogenicity in coagulase-negative staphylococci (Baddour et al., 1986; Kristinsson et al., 1986; Beaman et al., 1987).

\section{Materials and methods}

The investigation covered the 12-month period from March 1986 to February 1987 . The 55 patients undergoing CAPD at St Thomas' Hospital were swabbed at 6-week intervals at clinic visits for change of extension tubing. The following sites were sampled with a cotton-wool tipped swab (MW 130; Medical Wire and Equipment Co. Ltd, Corsham, Wilts) moistened with peptone water (Southern Group Laboratories, London): anterior nares, hand (non-dominant), axillae, umbilicus, groins, catheter, exit site, and connection between extension tubing and 
CAPD bag. Swabs were transferred to vials containing $0.2 \mathrm{ml}$ of glycerol $7 \%$ in Bacto Nutrient Broth (0003; Difco Laboratories, Detroit, USA) and frozen at $-70^{\circ} \mathrm{C}$, a technique permitting the recovery of staphylococci on skin swabs after prolonged storage (Ludlam et al., in press). Organisms were recovered by filtration from the dialysis effluent of patients presenting with peritonitis (Ludlam et al., 1988). Isolates of coagulase-negative staphylococci causing peritonitis were subcultured and stored at $-70^{\circ} \mathrm{C}$ in glycerol broth.

Coagulase-negative staphylococci on skin swabs were retrieved from storage by inoculating CLED agar (M12400; Gibco Ltd, Paisley, Scotland) in $140 \mathrm{~mm}$ diameter Petri dishes (501V; Sterilin Ltd, Feltham, Middlesex). Plates were incubated for 2 days at $37^{\circ} \mathrm{C}$ and then transferred to room temperature in the light for a further 5 days. Each different type of colony was noted and the predominance of growth recorded. Staphylococci were initially identified by colonial appearance and Gram's stain. Two colonies of each morphologically distinct staphylococcus were picked from the plate and subcultured to blood agar purity plates (horse blood $6 \%$ in Oxoid Columbia Agar base, CM331; Oxoid Ltd, Basingstoke). Single colonies of coagulase-negative staphylococci were picked from these purity plates for typing. The typing scheme was constructed in four stages: antibiogram with limited biotype, biochemical profile with speciation (API-Staph; API Products Ltd, Basingstoke, Hampshire), phage type, and plasmid profile. This scheme has performed satisfactorily in typing coagulasenegative staphylococci from CAPD peritonitis, with a discrimination of $76 \%$ and reproducibility of $86 \%$ (Ludlam et al., 1989).

The infecting (peritonitis) isolate was retrieved from glycerol broth at $-70^{\circ} \mathrm{C}$ by subculture to a blood agar purity plate, incubated overnight at $37^{\circ} \mathrm{C}$ and typed by the same scheme. Variability in the antibiogram and biochemical profile of the infecting strain was monitored by examining 10 colonies from the purity plate. Isolates of coagulase-negative staphylococci from the skin were considered to be the same as the infecting strain if they were indistinguishable by the typing scheme.

The infecting strain, indistinguishable skin strains and all other skin isolates distinguishable by antibiogram and biochemical profile, derived from swabs taken in the 2 weeks before peritonitis, were tested for adherence and slime production by modifications of the methods of Christensen et al. (1985). Briefly, the test organisms, and positive and negative control organisms, were grown in duplicate in Tryptone Soya Broth overnight in glass vials. The broth and sediment were decanted and the inside of the vial gently washed with saline. Adherent bacterial cells were stained by the addition of a $0.05 \%$ solution of crystal violet (BDH Ltd, Dagenham) to one vial; slime was stained by adding a $0.5 \%$ solution of alcian blue (BDH Ltd) to the duplicate vial. After staining, excess dye was decanted and the vials rinsed once more with saline. Ethanol was used to extract the crystal violet, and concentrated hydrochloric acid was used to solubilise the alcian blue complex. Both suspensions were then trans- ferred to microtitration trays and the optical density read with a Dynatech MR 700 ELISA reader (Dynatech Ltd, Billingshurst).

The history and clinical findings of patients presenting with peritonitis were recorded prospectively. Details of any factor that might have been responsible for the development of peritonitis (e.g., breach in aseptic technique or leak of dialysate from the exit site) were also recorded.

The statistical significance of difference between percentages was assessed by standard error of percentage difference (Swinscow, 1977).

\section{Results}

During the 12-month study, the 55 patients were swabbed on 256 occasions and experienced 36 episodes of peritonitis caused by coagulase-negative staphylococci. Ten episodes, affecting six patients, for which prospective serial skin swabs were available, and in which the patient had been swabbed in the 2 weeks preceding the episode, were selected for analysis.

\section{Characterisation of infecting strains}

Seventeen infecting strains were recovered from the 10 episodes of peritonitis (table I). Fifteen were characterised as Staphylococcus epidermidis (three biotypes), two as $S$. simulans (one biotype). Isolates from only four episodes were phage typable (each distinct), but all were typable by plasmid electrophoresis, which demonstrated 14 distinct profiles. All isolates were antibiotic resistant, with 13 distinct profiles.

\section{Variability in infecting strains}

Four of the 17 strains lost antibiotic resistance on subculture. This occurred in only one of the 10 subcultures, for each strain (table I). In each case this loss of resistance generated an isolate with a sensitivity pattern identical to that of a second infecting strain recovered from the dialysate, which was found to differ from the first strain in the lack of a single plasmid. As the biochemical profile and phage type of these pairs were the same, these results suggest that the second strains were derived from the first by plasmid loss in vivo.

The biochemical profile showed no variation in any subculture.

\section{Distribution of indistinguishable skin strains}

The infecting strains were found on the prospective skin swabs in six of the 10 episodes (episodes 
Table I. Characteristics of infecting strains

\begin{tabular}{|c|c|c|c|c|c|c|c|c|c|}
\hline $\begin{array}{l}\text { Patient, episode, } \\
\text { strain }\end{array}$ & $\mathrm{H}$ & M & $\mathrm{L}$ & Antibiogram & $\begin{array}{l}\text { Biotype and } \\
\text { species }\end{array}$ & Phage type & $\begin{array}{l}\text { Plasmid } \\
\text { profile }\end{array}$ & Adherence & $\begin{array}{c}\text { Slime } \\
\text { production }\end{array}$ \\
\hline $\begin{array}{rr}\text { A } 1.1 \\
.2\end{array}$ & $\begin{array}{l}- \\
-\end{array}$ & $\begin{array}{l}- \\
-\end{array}$ & $\begin{array}{l}- \\
-\end{array}$ & $\left.\begin{array}{l}\mathrm{b} \text { e } \mathrm{f} \operatorname{tm} \mathrm{t}^{*} \\
\mathrm{~b} \text { e f } \mathrm{tm}\end{array}\right\}$ & $\begin{array}{l}6206113 \\
\text { S. epidermidis }\end{array}$ & $27 \mathrm{~A} 6 \mathrm{C} 71$ & $\left\{\begin{array}{l}1 \\
1 \dagger\end{array}\right.$ & $\begin{array}{l}- \\
-\end{array}$ & $\begin{array}{l}- \\
-\end{array}$ \\
\hline A $\begin{array}{r}2.1 \\
.2\end{array}$ & - & - & $\begin{array}{l}+ \\
+\end{array}$ & $\left.\begin{array}{l}\text { b pgetmct* } \mathrm{t}^{*} \\
\text { bpgetmc }\end{array}\right\}$ & $\begin{array}{l}6606113 \\
\text { S.epidermidis }\end{array}$ & $\begin{array}{l}155 \text { A6C } 456 \\
471 \mathrm{~A} 495 \quad \mathrm{~B} 1\end{array}$ & $\left\{\begin{array}{l}2 \\
2 \dagger\end{array}\right.$ & $\begin{array}{l}- \\
-\end{array}$ & - \\
\hline $\begin{array}{r}\text { B } 3.1 \\
.2\end{array}$ & $\begin{array}{l}+ \\
+\end{array}$ & $\begin{array}{l}- \\
-\end{array}$ & $\begin{array}{l}+ \\
+\end{array}$ & $\left.\begin{array}{l}\text { bpgetmc* } \\
\text { bpgetm }\end{array}\right\}$ & $\begin{array}{l}6606113 \\
\text { S. epidermidis }\end{array}$ & NT & $\left\{\begin{array}{l}3 \\
3 \dagger\end{array}\right.$ & - & $\begin{array}{l}- \\
-\end{array}$ \\
\hline C 4.1 & + & + & + & $\mathrm{bp}$ & $\begin{array}{l}6436153 \\
\text { S. simulans }\end{array}$ & NT & 4 & - & - \\
\hline .2 & - & - & + & bpe tmcg & $\begin{array}{l}6606113 \\
\text { S. epidermidis }\end{array}$ & NT & 5 & - & - \\
\hline C 5.1 & + & + & + & $\mathrm{bp}$ & $\begin{array}{l}6436153 \\
\text { S. simulans }\end{array}$ & NT & 4 & - & - \\
\hline $\begin{array}{l}.2 \\
.3\end{array}$ & $\begin{array}{l}- \\
-\end{array}$ & $\begin{array}{l}- \\
-\end{array}$ & $\begin{array}{l}+ \\
+\end{array}$ & $\left.\begin{array}{l}\text { b pe tm } \mathrm{cg}^{*} \\
\text { b petmc }\end{array}\right\}$ & $\begin{array}{l}6606113 \\
\text { S. epidermidis }\end{array}$ & NT & $\left\{\begin{array}{l}5 \\
5 \dagger\end{array}\right.$ & - & - \\
\hline D 6.1 & - & - & + & $\mathrm{be}$ & $\begin{array}{l}6604112 \\
\text { S. epidermidis }\end{array}$ & NT & 6 & - & - \\
\hline D 7.1 & - & - & + & $\mathrm{be}$ & $\begin{array}{l}6604112 \\
\text { S. epidermidis }\end{array}$ & NT & 6 & - & - \\
\hline E 8.1 & - & - & + & $\mathrm{bp}$ & $\begin{array}{l}6606113 \\
\text { S. epidermidis }\end{array}$ & NT & 7 & - & - \\
\hline F 9.1 & + & - & + & b p g tm & $\begin{array}{l}6606113 \\
\text { S. epidermidis }\end{array}$ & NT & 8 & + & + \\
\hline .2 & + & - & + & $\mathrm{bpn}$ & $\begin{array}{l}6606113 \\
\text { S. epidermidis }\end{array}$ & $471 \mathrm{~A}$ & 9 & + & + \\
\hline F 10.1 & - & - & + & $\mathrm{bptftm}$ me & $\begin{array}{l}6606113 \\
\text { S. epidermidis }\end{array}$ & $456,471 \mathrm{~A}$ & 10 & - & - \\
\hline
\end{tabular}

$\mathrm{H}=$ Haemolysis $(+=$ haemolytic $)$.

$\mathbf{M}=$ Mannitol fermentation $(+=$ fermenter $)$.

$\mathrm{L}=$ Lactose fermentation $(+=$ fermenter $)$.

$\mathrm{b}=$ bacitracin, $\mathrm{p}=$ penicillin, $\mathrm{g}=$ gentamicin, $\mathrm{t}=$ tetracycline, $\mathrm{e}=$ erythromycin,

$\mathrm{f}=$ fusidic acid, $\mathrm{tm}=$ trimethoprim, $\mathrm{c}=$ chloramphenicol, $\mathrm{me}=$ methicillin, $\mathrm{n}=$ neomycin .

$\mathrm{NT}=$ not typable.

* Antibiotic to which resistance to which resistance was lost in variability study.

$\uparrow$ Plasmid profile differs in lacking one plasmid.

2, 3, 4, 5, 9 and 10), including the three episodes each caused by two unrelated strains of coagulasenegative staphylococci. Seven of the nine strains were $S$. epidermidis, the other two were $S$. simulans. The location of these nine indistinguishable strains in time and place, is presented in table II and summarised in the figure (data for infecting strains has been combined where these differed in antibiogram only, and the variability study and plasmid electrophoresis confirmed that this was due to plasmid loss). The likelihood of recovering the infecting organisms was increased nearer the time of peritonitis (figure). It was always found on swabs taken in the 2 weeks before the episode, usually found between 3 and 12 weeks, but never before this. By 2 weeks before the episode the organism was widely distributed (the axilla, unbilicus and connector were the sites most commonly colonised), usually as the predominant or equally predominant organism at each site (table II).

\section{Adherence and slime production}

Infecting strains. Only two $(12 \%)$ of the 17 infecting strains gave positive results in these tests (table I). Both were S. epidermidis and were derived from the same episode (9), but were otherwise unrelated.

Skin strains. The study as a whole generated 211 distinct strains for testing; $25 \%$ were adherent and $23 \%$ produced slime (tables III and IV). There was disagreement between these tests on only 15 


\begin{tabular}{|c|c|c|c|c|}
\hline \multirow{2}{*}{ SKIN SITE } & TEEKS & BEFORE & \multicolumn{2}{|c|}{ PERITONITIS } \\
\hline & $0-2$ & $3-6$ & $7-12$ & $13-24$ \\
\hline NOS E & OO & 8000 & $\begin{array}{l}0000 \\
00000\end{array}$ & $\begin{array}{l}0000 \\
00000\end{array}$ \\
\hline B A N D & 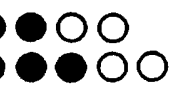 & .000 & $\begin{array}{l}0000 \\
00000\end{array}$ & $\begin{array}{l}0000 \\
00000\end{array}$ \\
\hline$A X I L L A$ & & 9000 & $\begin{array}{l}0000 \\
00000\end{array}$ & $\begin{array}{l}0000 \\
00000\end{array}$ \\
\hline U M B I L ICUS & & $\begin{array}{l}0000 \\
00000\end{array}$ & $\begin{array}{l}0000 \\
00000\end{array}$ & $\begin{array}{l}0000 \\
00000\end{array}$ \\
\hline$E X I T-S I T E$ & $\begin{array}{l}000 \\
0000\end{array}$ & $\begin{array}{l}0000 \\
00000\end{array}$ & $\begin{array}{l}0000 \\
00000\end{array}$ & $\begin{array}{l}0000 \\
00000\end{array}$ \\
\hline GROI N & $\begin{array}{l}000 \\
0000\end{array}$ & $\begin{array}{l}0000 \\
00000\end{array}$ & $\begin{array}{l}0000 \\
00000\end{array}$ & $\begin{array}{l}0000 \\
00000\end{array}$ \\
\hline CONNECTOR & & $\begin{array}{l}0000 \\
0000\end{array}$ & $\begin{array}{l}0000 \\
.0000\end{array}$ & $\begin{array}{l}0000 \\
00000\end{array}$ \\
\hline
\end{tabular}

Figure. Overall distribution of infecting strains: infecting strain found at site swabbed; $O$ infecting strain not found at site swabbed.

occasions ( $7 \%$ of all isolates). There were wide variations in the proportion of skin strains that gave positive results in these tests between patients : $0-64 \%$ and $0-48 \%$, for adherence and slime production, respectively.

\section{Statistical analysis}

Infecting strains were no more likely to be adherent or produce slime than skin strains $(12 \%$ versus $25 \%, \mathrm{p}=0.3$; and $12 \%$ versus $23 \%, \mathrm{p}=0 \cdot 3$, respectively). The infecting strains that were not found on the skin were no more likely to adhere or produce slime than the strains that were found on skin: $2(17 \%)$ of 12 versus $0(0 \%)$ of 5 positive $(p=0 \cdot 3)$ for both properties. There were significant differences amongst skin strains for these properties, $S$. epidermidis being more likely to be adherent and produce slime than other coagulase-negative staphylococci and micrococci (table IV); $37 \%$ of $S$. epidermidis were adherent and produced slime, whereas of the other isolates only $10 \%$ and $4 \%$ were positive, respectively. This difference is statistically significant $(\mathrm{p}<0.001)$.

\section{Clinical findings}

Episode 1. The patient was performing his own bag exchanges, at home. The patient was swabbed the day before onset of peritonitis, 3 days after accidentally touching the inside of the tubing's bag connection with his hand.

Episode 3. The patient was hospitalised, having received a Tenchkoff catheter 4 days before swabbing. A leak of dialysate had developed at the exit site on the day of swabbing, and the patient developed peritonitis the next day. Nursing staff were performing bag exchanges.

Episode 8. The patient was performing her own exchanges at home. She had been swabbed 3 days before an accidental disconnection of dialysis tubing from the titanium connector. Peritonitis developed 2 days later.

Episode 9. The patient was performing his own exchanges at home. He was swabbed the day before a leak of dialysate from the titanium connector; peritonitis developed the next day.

Episodes 2, 4, 5, 6, 7 and 10. No predisposing factors were associated with these episodes. All occurred in out-patients performing with their own bag exchanges. 
Table II. Distribution of infecting strains, and total distinguishable coagulase-negative staphylococci at each site

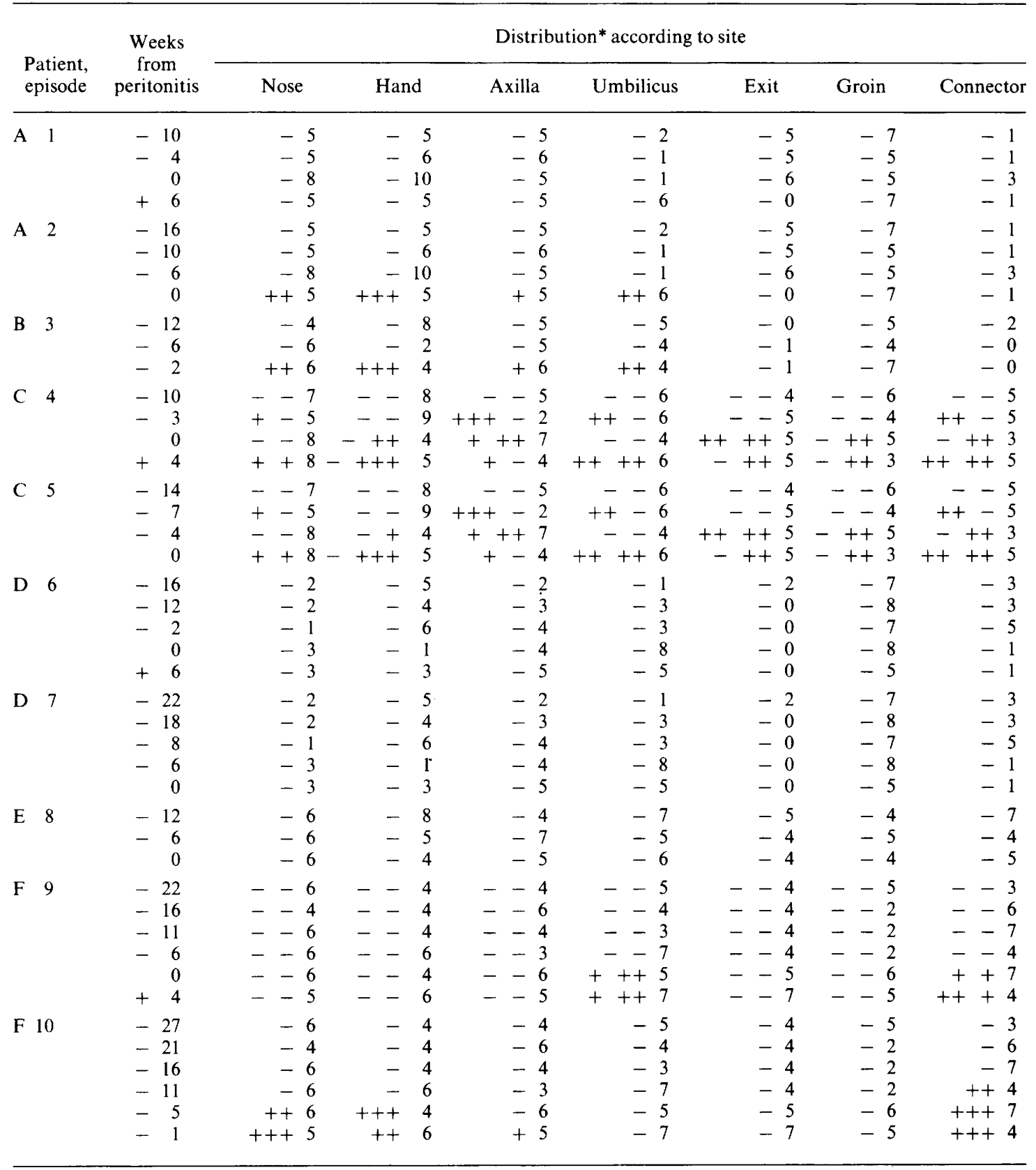

+++ Infecting strain found as the predominant skin strain.

++ Infecting strain found in equal numbers with other skin strains.

+ Infecting strain found in the minority.

- Infecting strain not found.

* Numerals refer to the total number of coagulase-negative staphylococci distinguishable by the antibiogram with limited biotype found at that site. 
Table III. Adherence and slime production of skin strains

\begin{tabular}{rrrr}
\hline & \multicolumn{3}{c}{ Distinct skin strains } \\
\cline { 2 - 4 } Episode & Total & $\begin{array}{c}\text { Number (\%) } \\
\text { adherent }\end{array}$ & $\begin{array}{c}\text { Number (\%) } \\
\text { producing slime }\end{array}$ \\
\hline 1 & 27 & $7(26)$ & $6(22)$ \\
2 & 15 & $1(7)$ & $3(20)$ \\
3 & 16 & $3(19)$ & $3(19)$ \\
4 & 16 & $0(0)$ & $0(0)$ \\
5 & 16 & $2(13)$ & $2(13)$ \\
6 & 18 & $1(6)$ & $1(6)$ \\
7 & 13 & $1(8)$ & $2(15)$ \\
8 & 30 & $6(20)$ & $4(13)$ \\
9 & 33 & $21(64)$ & $14(42)$ \\
10 & 27 & $11(41)$ & $13(48)$ \\
Total & 211 & $53(25)$ & $48(23)$ \\
\hline
\end{tabular}

\section{Correlation of clinical and laboratory findings}

The infecting strain was found in only two of the four episodes in which a predisposing cause was identified. In episode 3 , peritonitis was associated with a leak of dialysate at the exit site, but the infecting organism was not recovered from this site (although it was otherwise widely distributed). In episode 9 the patient developed peritonitis the day after experiencing a leak of dialysate from the titanium connector of the tubing. He had been swabbed the day before, and the infecting organism was found on the tubing at the bag connector (the titanium connector was not swabbed).

\section{Discussion}

A number of factors make the study of the epidemiology of infection with coagulase-negative staphylococci in patients receiving CAPD laborious. Effort will inevitably be wasted in the collection of the skin swabs, the majority of which will later prove to be irrelevant, since most patients will not develop peritonitis caused by these organisms. The ecology of coagulase-negative staphylococci is complex: in this study 50 isolates were screened in the average set of skin swabs, yielding 20 strains of coagulase-negative staphylococci distinguishable by antibiogram, with each site bearing five distinct strains. We employed two strategies to reduce this workload: we stored skin swabs in glycerol broth at $-70^{\circ} \mathrm{C}$ until the patient developed coagulasenegative staphylococcal peritonitis, and we employed a typing scheme with a simple yet highly discriminatory first stage, the antibiogram (Ludlam et al., 1989). Nevertheless, each episode in this study still required about one month of laboratory work.

Two other studies have attempted to establish the epidemiology of CAPD peritonitis caused by coagulase-negative staphylococci. Sewell et al. (1982) studied seven episodes of peritonitis and found coagulase-negative staphylococci indistinguishable from the infecting strain in all cases. This result was questionable, however, as isolates were typed by biotyping with the scheme of Kloos and Schleifer, only, which is poorly discriminatory. Eisenberg et al. (1987) corrected this deficiency by supplementing this scheme with typing by plasmid profile, in a study of 20 episodes of peritonitis. These workers, by contrast, recovered an indistinguishable organism from prospectively collected skin swabs in only three episodes. They suspected that this low rate of recovery was due to inadequate sampling methods. The results of the present study confirm this $; 83 \%$ of skin swabs in our study yielded multiple isolates, compared with $13 \%$ in the study of Eisenberg et al. We succeeded in recovering isolates indistinguishable from the peritonitis strain from prospectively collected skin swabs in six of the 10 episodes studied, employing a highly discriminatory typing scheme which included phage typing and the antibiogram in addition to the Kloos and Schleifer biotype and plasmid profile. Nevertheless, Eisenberg $e t$ al. also found evidence for transient carriage of the infecting strain, which we can confirm. Acquisition immediately before the onset

Table IV. Adherence and slime production by species (skin bacteria)

\begin{tabular}{lrcc}
\hline \multicolumn{1}{c}{ Organism } & $\begin{array}{c}\text { Number } \\
\text { of isolates }\end{array}$ & $\begin{array}{c}\text { Number }(\%) \\
\text { adherent }\end{array}$ & $\begin{array}{c}\text { Number }(\%) \\
\text { producing } \\
\text { slime }\end{array}$ \\
\hline S. epidermidis & 118 & $44(37)$ & $44(37)$ \\
S. haemolyticus & 27 & $2(7)$ & $2(10)$ \\
S. hominis & 20 & $4(20)$ & \\
S. simulans & 18 & & $1(50)$ \\
S. warneri & 6 & & $1(100)$ \\
S. cohnii & 3 & $2(100)$ & \\
S. intermedius & 2 & $1(100)$ & \\
S. hyicus & 1 & & \\
S. saprophyticus & 1 & & \\
S. sciuri & 1 & & \\
S. capitis & 1 & & \\
Micrococcus spp. & 13 & & \\
Total & 211 & $53(25)$ & \\
Organisms other & & & \\
than S. epidermidis & 93 & $9(10)$ & \\
\hline
\end{tabular}


of infection is one possible explanation for the failure to isolate the infecting organism in the other four episodes. Alternative possibilities are that the organisms were present at the sites swabbed, but in numbers too small to be detected, or were confined to an unswabbed site. A further possibility is that the infecting strain was derived directly from another person, if an airborne skin scale gained access to the peritoneal cavity during a bag exchange.

We have previously reported an association between a lapse in aseptic technique and the subsequent development of peritonitis (Ludlam et al., 1988), and our ability to substantiate this for only two of the four episodes where a predisposing factor was identified is disappointing. In the other two episodes we may have failed to swab the appropriate site at the appropriate time, or the predisposing factor may have been a coincidental finding and not the cause of the peritonitis.

Application of our typing scheme failed to demonstrate any feature of infecting strains that distinguished them from non-infecting strains. Furthermore, we cannot confirm previous reports that infecting strains of coagulase-negative staphylococci are more likely to produce slime (Kristinsson et al., 1986; Beaman et al., 1987), or be adherent (Baddou et al., 1986), than non-infecting strains. Our findings support those of West et al. (1986) and Alexander and Rimland (1987) who found no such correlation. The single episode in which the infecting strains were adherent and produced slime occurred in the patient with the highest proportion of skin strains positive for these properties.

Coagulase-positive and coagulase-negative

\section{REFERENCES}

Alexander W, Rimland D 1987 Lack of correlation of slime production with pathogenicity in continuous ambulatory peritoneal dialysis peritonitis caused by coagulase negative staphylococci. Diagnostic Microbiology and Infectious Diseases 8: 215-220.

Baddour L M, Smalley D L, Kraus A P, Lamoreaux W J, Christensen G D 1986 Comparison of microbiologic characteristics of pathogenic and saprophytic coagulasenegative staphylococci from patients on continuous ambulatory peritoneal dialysis. Diagnostic Microbiology and Infectious Diseases 5: 197-205.

Beaman M, Solaro L, Adu D, Michael J 1987 Peritonitis caused by slime-producing coagulase negative staphylococci in continuous ambulatory peritoneal dialysis. Lancet 1 : 42.

Bint A J, Finch R G, Gokal R, Goldsmith H J, Junor B, Oliver D 1987 Diagnosis and management of peritonitis in continuous ambulatory peritoneal dialysis. (Report of a Working Party of the British Society for Antimicrobial Chemotherapy) Lancet 1 : 845-849. staphylococci are the commonest causes of CAPD peritonitis. The present study has demonstrated that approximately two-thirds of patients developing peritonitis caused by coagulase-negative staphylococci carried the infecting strain on the skin before the episode of peritonitis. We have found the same to be true for patients developing peritonitis caused by coagulase-positive staphylococci (Ludlam et al., unpublished data). By eradicating carriage of $S$. aureus at the nose, groin and Tenckhoff catheter exit sites of our patients we achieved a 10 -fold reduction in the peritonitis rate for $S$. aureus. The peritonitis rate for coagulasenegative staphylococci was, however, unchanged. The present study provides the explanation for this finding : carriage of the infecting strain of coagulasenegative staphylococcus, when demonstrated, was widespread, and not confined to the nose, groin and rxit site. This widespread and unpredictable distribution would make any similar attempt to prevent coagulase-negative peritonitis through eradication of skin carriage extremely difficult. A more fruitful approach to the prevention of peritonitis caused by coagulase-negative staphylococci has been reported by Maiorca et al. (1983), who developed a technique for flushing out contaminating organisms which have entered the Tenckhoff catheter tubing during dialysate bag exchanges.

We are grateful to Mrs Mary Rahman, who performed the plasmid profiles, and to Drs N. F. Jones, A. J. Wing and P. J. Hilton for permission to study their patients. Mrs Rahman was supported by a grant from the National Kidney Research Fund H A L was supported by a grant from St Thomas' Hospital Research Endowments.

Christensen G D et al. 1985 Adherence of coagulase-negative staphylococci to plastic tissue culture plates: a quantitative model for the adherence of staphylococci to medical devices. Journal of Clinical Microbiology 22: 996-1006.

Eisenberg E S, Ambalu M, Szylagi G, Aning V, Soeiro R 1987 Colonization of skin and development of peritonitis due to coagulase-negative staphylococci in patients undergoing peritoneal dialysis. Journal of Infectious Diseases 156: 478482.

Hartstein A I, Valvano M A, Morthland V H, Fuchs P C, Potter S A, Crosa J H 1987 Antimicrobic susceptibility and plasmid profile analysis as identity tests for multiple blood isolates for coagulase-negative staphylococci. Journal of Clinical Microbiology 25: 589-593.

Kloos W E, Schleifer K H 1975 Simplified scheme for routine identification of human Staphylococcus species. Journal of Clinical Microbiology 1 : 82-88.

Kristinsson K G, Spencer R C, Brown C B 1986 Clinical importance of production of slime by coagulase negative staphylococci in chronic ambulatory peritoneal dialysis. Journal of Clinical Pathology 39: 117-118.

Ludlam H A, Price T N C, Berry A J, Phillips I 1988 Laboratory 
diagnosis of peritonitis in patients on continuous ambulatory peritoneal dialysis. Journal of Clinical Microbiology 26: 1757-1762.

Ludlam H A, Noble W C, Marples R R, Phillips I 1989 The evaluation of a typing scheme for coagulase-negative staphylococci suitable for epidemiological studies. Journal of Medical Microbiology 30: 161-165.

Ludlam H A, Nwachukwu B, Noble W C, Swan A V, Phillips I The presentation of micro-organisms in biological specimens stored at $-70^{\circ} \mathrm{C}$. Journal of Applied Bacteriology, in press.

Maiorca R et al. 1983 Prospective controlled trial of a Yconnector and disinfectant to prevent peritonitis in continuous ambulatory peritoneal dialysis. Lancet 2 : 642-644.
Parisi J T, Hamory B H 1986 Simplified method for the isolation, identification and characterisation of Staphylococcus epidermidis in epidemiological studies. Diagnostic Microbiology and Infectious Diseases 4: 29-35.

Sewell C M, Clarridge J, Lacke C, Weinman E J, Young E J 1982 Staphylococcal nasal carriage and subsequent infection in peritoneal dialysis patients. Journal of the American Medical Association 248: 1493-1495.

Swinscow T D V 1977 Statistics at square one, 2nd edn. British Medical Association, London, pp 28-32.

West T E, Walshe J J, Krol C P, Amsterdam D 1986 Staphylococcal peritonitis in patients on continuous peritoneal dialysis. Journal of Clinical Microbiology 23: 809-812. 